\title{
CORRELAÇÃO ENTRE CARTA-PROTESTO E HISTÓRICO DE LETRAMENTO DO CANDIDATO: UMA ANÁLISE DE REDAÇÕES DO VESTIBULAR
}

\author{
Elizabeth Maria da Silva* \\ Denise Lino de Araújo**
}

Resumo: Tendo em vista que algumas instituições, a exemplo da Universidade Federal de Campina Grande (UFCG), vêm requisitando, na prova de redação, a escrita de um gênero textual e não mais da dissertação, tradicionalmente solicitada na escola e na maioria dos vestibulares, este artigo objetiva (1) averiguar as práticas letradas requeridas na produção da carta-protesto proposta na prova de redação do vestibular da UFCG 2007 e (2) investigar a correlação entre as práticas demonstradas pelos candidatos na produção da carta e seu histórico de letramento. Para tal, foi realizada uma pesquisa descritivointerpretativa cujo corpus foi constituido pela prova aplicada no vestibular referido, bem como por uma amostragem de cartas produzidas nesse evento, além de entrevistas realizadas com os candidatos. Os dados, analisados com base nos estudos sobre letramento crítico (BARTON; HAMILTON, 2000; GEE, 2000), indicam que o bistórico de letramento dos candidatos parece ser fator decisivo para a mobilização de práticas letradas na redação.

Palavras-chave: Cartas-protesto. Práticas Letradas. Histórico de Letramento.

\section{INTRODUÇÃO}

Nos últimos anos, Silva e Lino de Araújo (2005; 2006a; 2006b; 2006c; 2006d, 2010) vêm desenvolvendo pesquisas sobre redação de vestibular, cujos resultados têm evidenciado o efeito retroativo ${ }^{1}$ da teoria de gêneros textuais na elaboração das provas de redação aplicadas pela

\footnotetext{
Professor Assistente da UFCG; Mestre em Linguagem e Ensino. Email: <professoraelizabethsilva@gmail.com>.

** Professor Adjunto da UFCG; Doutora em Educação. Email: <linodenise@yahoo.com.br>.

${ }^{1} \mathrm{O}$ efeito retroativo é o impacto ou a influência que mecanismos de avaliação podem exercer no processo de ensino/aprendizagem, bem como nos seus participantes e no produto desse processo (cf. SCARAMUCCI, 2001).
} 
Universidade Federal de Campina Grande (UFCG). Desde 2005², os candidatos são incumbidos de produzir um gênero - artigo de opinião ou relato de experiência (UFCG 2005); depoimento ou carta- denúncia (UFCG 2006); carta-protesto ou memória (UFCG 2007); reportagem ou análise de poemas (UFCG 2008); abaixo-assinado ou artigo jornalístico (UFCG 2009) e diálogo ou anúncio publicitário (UFCG 2010).

Tendo em vista esse redirecionamento na prova de redação (a exigência de gêneros diversos), produzimos uma pesquisa, que resultou em uma dissertação de mestrado (SILVA, 2009), objetivando analisar que correlação poderia ser estabelecida entre as práticas letradas mobilizadas nas redações e o histórico de letramento dos candidatos. Vale esclarecer que, até o momento, desconhecemos na literatura trabalhos em que o histórico de letramento seja explicitamente definido pelos pesquisadores. Kleiman (2006, p. 29, 31, 35), por exemplo, diz que as relações entre os saberes não escolares e os disciplinares merecem ser exploradas pelos professores e agentes de letramento na escola. Diz também que a estratégia para a construção de relações entre as práticas não escolares e as escolares envolve a observação e identificação de questões sociais de cidadania, de identidade e de inclusão. Por fim, destaca a inserção de práticas letradas de múltiplas instituições nos projetos escolares. Todavia, não se refere ao fato de que a convivência com práticas escolares e não escolares, advindas de diversas agências com as quais o sujeito mantém contato, se influenciam mutuamente e formam o seu histórico de letramento, tal como defendemos neste trabalho.

Nesse sentido, na pesquisa referida, desenvolvemos, grosso modo, uma definição para essa expressão, qual seja, experiências que os sujeitos dizem ter em relação às práticas de leitura e de escrita em diferentes situações comunicativas.

No presente artigo, apresentaremos uma parte dos resultados obtidos a partir da realização da pesquisa referida. Nesse sentido, traçamos dois objetivos: (1) averiguar as práticas letradas requeridas na produção da carta-protesto proposta na prova de redação aplicada no

\footnotetext{
${ }^{2} \mathrm{O}$ vestibular aplicado por essa instituição é relativamente recente, já que a UFCG se desmembrou da Universidade Federal da Paraíba em 2002. Desde o primeiro ano da realização do seu processo seletivo, a prova de redação é pautada na solicitação da escrita de gêneros textuais.
} 
vestibular da UFCG em 2007 e (2) analisar as associações entre a mobilização de práticas letradas na produção das cartas e o histórico de letramento dos candidatos que as produziram.

Quanto aos aspectos metodológicos, realizamos uma pesquisa de natureza descritivo-interpretativa (cf. ANDRÉ, 1995). Como já dito, o presente artigo integra um estudo mais amplo, cujo corpus foi constituído de quatro conjuntos de dados: (1) provas de redação aplicadas nos vestibulares regular e especial ${ }^{3}$ da UFCG, em 2007; (2) amostragem de redações produzidas nesses vestibulares; (3) questionário socioeconômico e cultural elaborado e aplicado pela Comissão de Processos Vestibulares (COMPROV) e (4) entrevista realizada pela pesquisadora com os candidatos cujas redações foram selecionadas.

Neste trabalho focalizaremos, a partir do procedimento de triangulação de dados, a prova aplicada no vestibular regular, bem como uma amostragem de cartas produzidas nesse evento, as quais foram coletadas aleatoriamente e depois categorizadas em: (i) cartas nas quais os candidatos demonstraram as práticas requeridas na prova; (ii) demonstraram parcialmente e (iii) não as demonstraram. Fará parte também desse procedimento de triangulação a entrevista realizada com os candidatos cujas cartas, representativas da segunda categoria citada, foram selecionadas. Essa entrevista foi realizada ora por telefone, ora por e-mail, conforme a solicitação dos próprios sujeitos, já que muitos moravam distantes do polo da pesquisa. Para isso, foram formuladas algumas questões discursivas com o objetivo de conhecer um pouco do histórico de letramento desses sujeitos, suas práticas de leitura e escrita, assim como sua experiência com o gênero produzido no vestibular. Vale esclarecer que o presidente da Comissão de Processos Vestibulares da UFCG autorizou a coleta dos dados, porém, em nenhum momento da pesquisa foi divulgado o nome dos candidatos envolvidos nesse processo investigativo.

Quanto à organização do presente artigo, dividimo-lo em cinco partes. Na primeira, apresentamos esta introdução; na segunda, explicitamos os princípios teóricos adotados; na terceira etapa, fizemos a

\footnotetext{
${ }^{3} \mathrm{O}$ vestibular especial é realizado no meio do ano. Nesse vestibular, são abertas inscrições para um número menor de cursos, os quais são oferecidos nos campi da UFCG localizados em cidades circunvizinhas a Campina Grande.
} 
análise tanto da proposta de produção da carta, quanto de redações produzidas como resposta a tal proposta; na quarta, tecemos as considerações finais e, por fim, na quinta e última parte, listamos as referências citadas ao longo do texto.

\section{REFERENCIAL TEÓRICO}

\subsection{Elementos constitutivos do letramento: agências, eventos e práticas}

Defender que não há um Letramento com "L" maiúsculo e "o" no singular, porém múltiplos letramentos situados em contextos sociais e culturais nas sociedades em que surgem, significa atribuir-lhes o mesmo valor e, ao mesmo tempo, reconhecer a existência de letramentos associados com diferentes áreas da vida dos sujeitos - familiar, política, religiosa, educacional, profissional, entre outras. Tais áreas são denominadas agências de letramento (cf. KLEIMAN, 2001; ROJO, 2001; BARTON; HAMILTON, 2000 e GEE, 2000), as quais ultrapassam a concepção de lugar/ambiente físico, referindo-se a um espaço sociodiscursivo, no qual há eventos de letramento regidos por práticas letradas construídas socialmente pelos sujeitos participantes das agências.

Os eventos são definidos por Barton e Hamilton (2000) como atividades nas quais o letramento tem um papel. Na maioria das vezes, são atividades que têm textos escritos envolvidos para serem lidos ou para se falar sobre eles, sendo a discussão sobre esses textos o ponto central, uma vez que a preocupação maior é como a escrita é produzida e usada pelos sujeitos. Na definição de eventos dada por Heath (1983, p. 93), notamos também a referência à presença do texto como básica para a interação: "qualquer ocasião em que uma peça escrita integra a natureza da interação entre os participantes e seus processos e estratégias interpretativos".

Com isso, podemos dizer que os eventos de letramento são situações comunicativas mediadas por textos escritos. Ao destacarmos a palavra mediadas, queremos dizer que, para ser um evento, não é necessária a presença de um texto escrito graficamente, mas que a ideia de um certo texto seja retomada oralmente. 
Os resultados de uma pesquisa realizada por Rojo (2001) indicam que as interações em sala de aula são verdadeiros eventos de letramento, quase todos viabilizados oralmente. Esses resultados evidenciam que:

[...] caso tenhamos ou não um texto escrito empírico em sala de aula; caso se trate ou não de leitura ou produção de textos escritos; mesmo caso apenas tenhamos um questionário oral [...] que se desenrole ao longo da aula, sempre se tratarão de eventos de letramento. (ROJO, 2001, p. 245)

Em outras palavras, a escrita está sempre permeando as interações em sala de aula e as formas em que ela se manifesta.

Lopes (2006), por sua vez, sinaliza que não só na sala de aula, mas também em outros espaços, a escrita também é retomada a partir de eventos de letramento. A autora mostrou que na Vila Irmã Dulce, foco de sua pesquisa, embora os moradores tenham dito que não tinham contato com a escrita, as experiências relatadas para a pesquisadora demonstraram o contrário; participavam em diferentes eventos: compra e venda de mercadorias; negociação em banco; sessões de leitura; anotações; envio e recebimento de bilhetes e cartas, entre outros.

Alguns eventos de letramento, como a prova de redação do vestibular, são de natureza complexa, haja vista que sugerem ao sujeito mais de uma posição social, uma vez que ele irá produzir a redação e deverá substituir sua posição social primeira, candidato a uma vaga no vestibular, por outra posição, cidadão atuante em prol das melhorias da condição do homem do campo, no caso aqui focalizado. A mudança dessa posição social é evidenciada no texto a partir de marcas deixadas pelo sujeito, conforme veremos na subseção 3.2.

O conceito de evento de letramento suscita outro conceito, o de práticas letradas. Segundo Barton e Hamilton (2000), as práticas de letramento são maneiras culturais como as pessoas usam a língua escrita na sua vida. Sendo maneiras culturalmente construídas, não é permitido às pessoas utilizarem a língua da forma que quiserem, com quem optarem, onde escolherem. As práticas, assim como os eventos, são formadas por regras sociais que regulam o uso e a distribuição dos textos, prescrevendo quem pode produzir ou ter acesso a esses textos. A 
diferença entre os conceitos, a nosso ver, é que, enquanto os eventos são regidos por regras estabelecidas pelas agências de letramento, as práticas seguem normas estabelecidas pelos eventos. É como se o evento estivesse para a agência assim como as práticas estão para o evento.

Em suma, os três conceitos apresentados nesta subseção servirão de base para a análise dos dados, haja vista que estamos entendendo a redação de vestibular como um evento de letramento, dentre os vários que aparecem na agência acadêmica, e, como tal, está sujeito às normas que regem essa agência. Além disso, considerar a redação como um evento implica reconhecê-la como uma situação comunicativa consolidada na agência acadêmica, de maneira que possui suas características e peculiaridades que a diferenciam de outros eventos, inclusive daqueles que também aparecem na agência referida. Ademais, assim como qualquer evento de letramento, a redação requisita algumas práticas letradas, outro conceito relevante para a pesquisa em foco, já que por meio dele, será possível descrever e analisar as exigências na produção do evento em questão, conforme veremos na seção 3 .

\subsection{A constituição do histórico de letramento}

Dentre as concepções de letramento existentes - Autônoma e Ideológica (STREET, 1984), Crítica (BARTON; HAMILTON, 2000 e GEE, 2000), Pragmática (MEY, 2001) e Retórica (BAZERMAN, 2007), optamos pela Crítica. Nessa concepção, as práticas de leitura e de escrita são entendidas a partir da correlação entre o contexto sócio-histórico e ideológico e a história de vida do sujeito. No universo dessa história de vida, acreditamos que uma categoria poderia ser observada, qual seja, o histórico de letramento - a experiência que o sujeito diz ter com práticas letradas diversas. Discorremos um pouco sobre essa categoria ao longo desta subseção.

Partindo do pressuposto de que estamos imersos em uma sociedade cada vez mais dinâmica e complexa e que, em consequência disso, temos a possibilidade de ter acesso a diferentes tipos de letramento, há sujeitos não apenas letrados em uma dada agência, mas multiletrados. Em função de estarem, muitas vezes, em contato com diferentes tipos de letramento - familiar, religioso, midiático, digital, 
escolar, entre outros -, esses sujeitos demonstram práticas de escrita diferenciadas oriundas desses letramentos.

Nesse sentido, entendemos que a escola parece não ser mais a principal agência de letramento, como defende Kleiman (1995); outras agências, como a midiática (cf. LINO DE ARAÚJO, 2004), a religiosa e a familiar, vêm ganhando espaço socialmente e influenciando cada vez mais os sujeitos. Silva (2009) percebeu que o atendimento às práticas requeridas pela prova de redação deu-se mais pelo contato que alguns candidatos tinham com o letramento literário, familiar, religioso e midiático do que com o escolar.

Com isso, começa-se a reconhecer eventos e práticas de letramento em variadas agências, tais como a igreja, a escola, os sindicatos, como bem destacam Barton e Hamilton (2000, p. 11): "há diferentes letramentos associados a diferentes domínios de vida, como a família, o trabalho e a escola".

Diferentemente da alfabetização, que é temporária e termina assim que o sujeito conclui seus primeiros anos de escolarização, o letramento é um processo constante e infinito, visto que, a cada dia, novas agências, novas situações sociocomunicativas surgem e, consequentemente, novos tipos de letramento, novos eventos, exigindo determinadas práticas letradas, às vezes peculiares, às vezes já conhecidas, apenas atualizadas. $\mathrm{O}$ contato com tais práticas contribui para a constituição do histórico de letramento dos sujeitos. Por isso, é importante conhecer esse histórico de letramento antes de analisar determinadas práticas por si mesmas, descontextualizadamente. O sujeito que escreve tem uma história, da qual não se desprende no momento de escrever seu texto, pelo contrário, recorre, em geral, a ela para atender às exigências de determinados eventos de letramento.

Há algumas pesquisas no campo do letramento crítico em que pesquisadores têm revelado que a história de vida de professores e de alunos de graduação é um dos elementos que interferem na atuação profissional dos mesmos, na sua prática em sala de aula.

Guedes-Pinto (2001), Guedes-Pinto et al. (2005) e Signorini (2005) analisaram relatos sobre a história de leitura de professores, averiguando que instâncias (escolar, religiosa, familiar, etc.) e/ou pessoas (pais, vizinhos, professores, etc.) contribuíram com o desenvolvimento da 
prática de leitura desses docentes. Semelhante trabalho foi realizado por Almeida (2001), que discutiu a correlação entre as práticas de leitura do professor, a constituição de uma identidade profissional e a atuação pedagógica.

Os estudos referidos mostram a influência da história de leitura dos docentes na sua atuação em sala de aula. Dependendo do contato que estabeleciam com as diferentes agências letradas, tendiam a incorporar as práticas letradas que regem os eventos de tais agências, de modo que as transferiam, muitas vezes, para outras agências. Práticas religiosas, familiares, acadêmicas transpareciam, em geral, na prática dos professores, e pareciam ser, na verdade, constitutivas desses sujeitos. Isso parece ratificar que a escola está dividindo, com outras agências letradas, seu poder de influenciar os sujeitos. Essas agências não são mais importantes do que aquela, mas sinalizadoras de que muitas práticas dos sujeitos são, muitas vezes, originárias, não necessariamente da própria escola, mas também de outras agências.

As pesquisas supracitadas são produtivas, haja vista que nos levam a pensar a respeito da influência que o histórico de letramento dos sujeitos pode exercer em suas atitudes, de maneira que estes podem realizar um processo de transposição de práticas letradas de um evento de letramento para outro. Sendo assim, entendemos que o histórico de letramento dos candidatos é um dos elementos que pode explicar as práticas letradas por eles demonstradas na prova de redação. Isso porque, dependendo das experiências de leitura e escrita que apresentam de forma geral e, de forma mais específica, as suas experiências relativas ao gênero produzido, eles tenderão, possivelmente, a atender ou não às práticas requeridas no evento, mobilizando aquelas que conhecem ou com as quais têm familiaridade.

\section{JOGOS ENUNCIATIVOS E HISTÓRICO DE LETRAMENTO}

Esta parte é constituída de duas subseções. Na primeira, averiguamos as práticas letradas exigidas na produção da carta-protesto; na segunda, correlacionamos as práticas demonstradas por dois candidatos com seu histórico de letramento. Vale esclarecer que se trata 
de um estudo por amostragem, no qual observamos que, do universo de 10 redações analisadas, em 8 , os candidatos ingressaram na situação comunicativa inerente à prova. $\mathrm{Na}$ segunda subseção, focalizaremos duas produções textuais que evidenciam tal constatação.

\subsection{Práticas requeridas nas provas de redação}

Observando a prova de redação aplicada em 2007 no vestibular da UFCG, notamos, à semelhança das provas realizadas em 2005 e 2006 (cf. SILVA e LINO DE ARAÚJO, 2006a), a apresentação de uma proposta textual na qual são indicados dois gêneros (carta-protesto e memória) dos quais os candidatos deveriam escolher apenas um para produzir. Tendo-o escolhido, os vestibulandos deveriam atender a, pelo menos, três práticas letradas, a saber: adesão à situação comunicativa proposta na prova, adequação do texto ao tema proposto e uso do registro escrito formal da língua portuguesa. Vejamos de que forma essas práticas são requeridas na prova:

Ex.: 1

REDAÇÃO

Os textos "As viúvas do sertão", "Droga tipo exportação" e "Um negócio lucrativo" podem ajudá-lo(a) no recorte temático do gênero escolhido para produção. NÃO é permitido copiar fragmentos desses textos sem que sejam usados, com a indicação da fonte, para apoiar sua argumentação.

\section{CONTEXTUALIZAÇÃO}

A revista Nordeste está preparando a edição comemorativa de $1^{\circ}$ aniversário, com a criação de duas novas seções: Cartas e Memórias. O tema dessa edição comemorativa é a realidade difícil da zona rural, com destaque para as condições subumanas de sobrevivência das políticas públicas de fixação do homem no campo. Como conhecedor dessa realidade, escolha UMA das duas situações comunicativas apresentadas a seguir, para redigir seu texto, com, no mínimo, 20 linhas e, no máximo, 25, a ser enviado para a revista. 
Situação I

Imagine-se um cidadão atuante em prol das melhorias da condição do homem do campo e elabore uma CARTAPROTESTO, sobre o tema da edição da revista.

ATENÇÃO!!!!

CARTA-PROTESTO é entendida nesta prova como um gênero de texto, em que se discute um fato que gera insatisfação pessoal ou coletiva, com o objetivo de chamar a atenção da população para as possíveis soluções desse mesmo fato. $\mathrm{O}$ registro linguístico utilizado é o formal.

Situação II

Imagine-se como descendente de um homem do campo e elabore suas memórias referentes a experiências vividas na infância e adolescência.

ATENÇÃO!!!!

MEMÓRIA é entendida nesta prova como um gênero de texto, em que se recuperam experiências e lembranças de vida individuais ou coletiva, com um teor reflexivo/interpretativo, utilizando o registro formal da língua.

(Prova de redação do vestibular regular UFCG 2007)

Podemos observar na prova apresentada uma relação intragênero, já que no interior do gênero prova de redação é solicitada a produção de outros gêneros, carta-protesto e memória, para os quais são apresentadas condições de produção, a exemplo de objetivo do texto, público-alvo e ambiente de circulação.

Nessa relação intragênero, os candidatos deparam-se com duas situações comunicativas: a proposta pela prova - assumirem o papel social indicado nas instruções referentes ao gênero escolhido e escreverem para o locutor sinalizado - e outra inerente à prova - produzirem um texto com o objetivo de serem avaliados pela banca corretora do vestibular.

A inserção na situação comunicativa proposta na prova é uma das práticas letradas requeridas no evento prova de redação, como já dito. Podemos observá-la no início das instruções dadas para a produção do 
gênero, no item Situação, a partir do uso do verbo "imagine", cuja carga semântica aponta para uma escrita fundamentada numa criação, num convite para o candidato "esquecer" a sua posição social (vestibulando) e assumir outra: cidadão atuante em prol das melhorias da condição do homem do campo, no caso da produção da carta, foco deste trabalho.

Tendo assumido a posição indicada, o candidato deverá produzir o gênero escolhido para ser supostamente publicado em um meio de comunicação, Revista Nordeste. A referência a essa revista contribui para a simulação do contexto comunicativo do gênero apresentado, já que direciona a escrita da carta.

Essa situação comunicativa proposta na prova, assim como acontece normalmente na escola, não se concretiza efetivamente, mas serve para orientar a escrita dos candidatos, de modo que não pensem que a escrita é um dom (cf. SERCUNDES, 1998) e, portanto, que não é necessário conhecer o objetivo do texto nem o interlocutor-alvo antes de escrever. É característico desse gênero não circular publicamente, a menos que a instituição elaboradora do concurso decida publicar, em sites ou em livros, as melhores redações produzidas no vestibular, como acontece, por exemplo, com os textos escritos nos vestibulares da UNICAMP (2003).

A inserção na situação comunicativa da prova implica, além de adequar o texto às condições de produção, respeitar as estruturas composicionais dos gêneros, as quais não foram descritas na prova. Os candidatos foram alertados, no item ATENÇAO!!!, para o objetivo da produção da carta - discutir sobre um problema que está afetando a população e, ao mesmo tempo, alertá-la quanto à necessidade de buscar soluções para esse fato. Todavia, não foram instruídos quanto à forma de escrevê-la - local e data, saudação inicial, corpo da carta, saudação final e assinatura. Além disso, não foi destacada uma característica essencial desse gênero, a interação com o interlocutor do texto. A ausência dessas informações pode interferir no desempenho dos candidatos, dependendo das experiências que eles tenham com o gênero carta-protesto.

A exigência dessa primeira prática letrada aqui focalizada sinaliza que a banca elaboradora da prova de redação da UFCG está exigindo não apenas gêneros abordados na agência escolar, mas também em outras agências de letramento, a exemplo da midiática. Em virtude disso, 
aqueles que têm experiência com letramentos tendem a obter bons resultados na redação, ao passo que aqueles cuja experiência de escrita limita-se ao letramento escolar tendem a apresentar um desempenho pouco satisfatório, já que esse tipo de letramento parece não ser suficiente nem o único que pode ajudá-los a demonstrar as práticas letradas exigidas nas provas de redação (SILVA, 2009).

Em relação à segunda prática letrada requerida no evento focalizado - adequação do texto ao tema indicado -, os candidatos deveriam inserir-se na situação dada na prova, contemplando o seguinte tema: realidade difícil da zona rural, com destaque para as condições subumanas de sobrevivência das políticas públicas de fixação do homem no campo. Para o desenvolvimento desse tema, foi oferecida alguma contribuição temática, uma vez que os textos apresentados na prova de língua portuguesa - "As viúvas do sertão", "Droga tipo exportação" e "Um negócio lucrativo" tratavam, direta ou indiretamente, do tema focalizado na redação. Desse modo, os candidatos poderiam fazer referência, em suas produções, a esses textos, na condição de subsidiar a argumentação presente no gênero produzido, conforme orientação - Não copie partes dos textos, sem que sejam indicadas as fontes e sem que elas fundamentem sua argumentação on exposição.

O oferecimento de contribuição temática é outro elemento que caracteriza a situação comunicativa proposta na prova, pois, mesmo sendo um contexto de seleção, em que a avaliação é pautada única e exclusivamente no produto, a banca elaboradora da prova apresenta uma proposta de redação pautada na concepção de escrita como processo, como evento socialmente situado, fruto da relação intertextual.

Uma das características dessa concepção é a de que para escrever é preciso ter o que dizer, sendo a intertextualidade um fator importante para tal, visto que contribui com a consistência argumentativa apresentada pelo sujeito. Este poderá fazer, no seu texto, referência a outros textos, seja com o objetivo de concordar com as ideias expostas, seja com o de refutá-las - ao contrário da escrita vista como um dom, uma inspiração divina, na qual apenas a indicação do tema e do modelo de texto a ser escrito é considerada suficiente para que os candidatos escrevam a redação (cf. SERCUNDES, 1998). 
Nesse contexto, os candidatos deverão, além de atender às condições de produção e à estrutura composicional do gênero carta, demonstrar a prática relativa ao estabelecimento de relações intertextuais no seu texto, tomando como base os textos apresentados na prova. Para tal, deverão utilizar o registro escrito formal da Língua Portuguesa, terceira prática letrada requerida no evento.

Observamos, assim, como a situação comunicativa dada na prova é configurada: embora a redação deva ser escrita com fins avaliativos, situação inerente à prova, são apresentados, na proposta textual, elementos norteadores da produção em situações sociocomunicativas reais - produção do gênero solicitado, articulando a estrutura composicional específica às condições de produção dadas, assim como ao tema indicado. Cria-se, assim, uma simulação de textos reais, que circulam na sociedade, ampliando as práticas requeridas até então, as escolares, para outras, como as midiáticas. Desse modo, a prova de redação aqui focalizada (e as outras que vêm sendo elaboradas e aplicadas pela UFCG) configura-se como evento de letramento complexo, uma vez que requer práticas letradas oriundas de diferentes agências e não apenas da escolar.

Vale salientar que, por questões didáticas, fizemos uma análise em separado de cada uma das práticas letradas requeridas pela prova de redação, mas as consideramos imbricadas e interligadas. Por isso, a análise dos dados, que será apresentada na próxima subseção, está organizada em função da primeira prática letrada - adesão à situação comunicativa proposta na prova -, de modo que as outras duas práticas (adequação do texto ao tema e o uso do registro escrito formal) encontram-se diluídas nesta.

\subsection{Práticas letradas demonstradas pelos candidatos correlacionadas com o histórico de letramento}

No universo de 10 redações analisadas, em 8 os candidatos produtores, em vez de aderirem à situação comunicativa proposta na prova, ingressaram na situação comunicativa inerente à prova. Nessa segunda situação, eles colocaram-se na posição de vestibulandos que escrevem uma redação para a banca corretora com o objetivo de serem 
avaliados quanto a uma vaga no ensino superior e, nessa condição, produziram uma dissertação escolar. Sendo assim, destacaremos nesta subseção as características de duas das 8 redações analisadas que sinalizam o não atendimento às práticas letradas requeridas na prova em questão. Vejamos o texto produzido pelo candidato 1 .

Ex.: 2

Caros leitores

Já faz tempo que em nosso país observamos o descaso de nossos governantes em relação à construção de novas políticas públicas para solucionar os problemas da população. Isto fica bastante nítido quando observamos a situação daqueles que vivem na zona rural.

É uma população que vive às margens dos benefícios sociais como educação, saneamento, esgoto e saúde. A situação fica mais difícil se analizarmos como anda a dignidade humana. Todo ser humano deve ter o direito a ser sustentado por si mesmo, mas para isso é necessário que haja condição para tal fato acontecer.

Parece que os nossos governantes não se importam com isso, preferem ignorar a situação e criar programas com medidas populistas para permanecer no poder.

Existem casos em que o governo apoiou a população e deu certo. É o que acontece em algumas áreas no meio do sertão nordestino com irrigação artificial, que produzem frutos de ótima qualidade, sendo até exportados. Talvez se o povo tomasse consciência que tem voz, saberia falar mais alto, para que seu clamor chegasse até os governantes. Esses então, escutariam que o povo não quer depender de esmola, mas sim trabalhar e viver dignamente.

(assinatura) V. V. C. de S.

(Candidato 1 - Redação produzida no vestibular regular UFCG 2007)

Podemos verificar na redação apresentada que o vocativo utilizado no início da carta, Caros leitores, o uso do pronome possessivo "nosso(s)", nas expressões nosso país e nossos governantes, bem como a 
utilização de verbos em primeira pessoa do plural, observamos e analizarmos, revelam a tentativa do candidato 1 de ingressar na situação comunicativa da prova, dado que, procurando assumir a posição social de cidadão atuante em prol de melhores condições para o homem do campo, dirige-se à população, público- alvo da carta.

No entanto, tais marcas linguísticas evidenciam uma aparente participação do candidato 1 na situação, porque, a partir do segundo parágrafo do texto, esse candidato troca sua posição de cidadão, que está escrevendo para a população com o objetivo de alertá-la quanto aos problemas que afligem essa zona, para a de um escritor de dissertação a ser lida por um destinatário previamente definido no vestibular, o corretor de redações. Isso pode ser percebido a partir do distanciamento tomado pelo candidato que começa a argumentar em $3^{\mathrm{a}}$ pessoa do singular, de forma impessoal e objetiva - É uma população que vive às margens dos beneficios sociais como educação, saneamento, esgoto e saúde e Todo ser bumano deve ter o direito a ser sustentado por si mesmo, mas para isso é necessário que haja condição para tal fato acontecer.

A conclusão do texto constitui o ápice do abandono da inserção na situação comunicativa da prova, uma vez que o autor, ao propor uma alternativa de como lidar com os problemas do meio rural, distancia-se do interlocutor, atribuindo a esse a responsabilidade de agir em prol dos interesses do homem do campo, conforme sinaliza o uso da $3^{\text {a }}$ pessoa do singular - se o povo tomasse consciência (...) o povo não quer depender de esmola. Se tivesse assumido a posição social sinalizada na prova, não teria, provavelmente, se eximido do seu papel enquanto cidadão que defende os direitos dos homens rurais, pelo contrário, ter-se-ia incluído nessa missão, consequentemente, feito a sugestão em primeira pessoa do plural.

Notamos, assim, que a inserção de candidato 1 na situação comunicativa inerente à prova se fortalece, já que tal candidato não interagiu, até o final da carta, com os leitores. Além disso, não colocou no seu texto alguns elementos característicos da estrutura composicional das cartas - local, data (no início do texto) e expressão de despedida (final do texto) conforme prática letrada requerida pelo evento cartaprotesto. Os únicos traços característicos desse gênero, que aparecem no texto, são o vocativo e a assinatura, sendo aquele o mais peculiar em textos epistolares. Ademais, a interação com o destinatário, como já dito, 
é perceptível apenas na saudação inicial e na utilização da primeira pessoa do plural no primeiro e no terceiro parágrafos.

A dificuldade do candidato 1 em participar da situação comunicativa proposta na prova talvez se deva ao fato de que, conforme disse na entrevista, na terceira série do ensino médio, não havia redações e eu não havia estudado o gênero [carta-protesto], fator que deve ter levado o candidato 1 a escrever a dissertação, gênero escolar tradicionalmente ensinado nas escolas. Considerando que ele afirmou não ter estudado redação na terceira série do nível médio, o que não implica dizer que não o tenha feito nas séries anteriores, e cientes de que a dissertação é um gênero de tradição escolar, entendemos que o candidato 1, na redação de vestibular, mobilizou práticas escolares e ingressou na situação inerente da prova. Pudemos observar, no texto por ele escrito, algumas práticas letradas requeridas pela dissertação.

No primeiro parágrafo, ele apresenta a sua tese - [há um] descaso de nossos governantes em relação à construção de novas políticas públicas para solucionar os problemas da população.

No segundo, o vestibulando apresenta argumentos que procuram justificar por que a ausência de políticas públicas na zona rural é complicada - população vive às margens dos benefícios sociais como educação, saneamento, esgoto e saúde. A situação fica mais difícil se analizarmos como anda a dignidade humana. Tendo em vista tais problemas, argumenta que Todo ser humano deve ter o direito a ser sustentado por si mesmo, mas para isso é necessário que haja condição para tal fato acontecer.

No parágrafo seguinte, o autor continua a linha argumentativa, criticando os governantes - nossos governantes não se importam com isso, preferem ignorar a situação. Em seguida, apresenta contra-argumentos (também no último parágrafo) - criam programas com medidas populistas para permanecer no poder; Existem casos em que o governo apoiou a população e deu certo. É o que acontece em algumas áreas no meio do sertão nordestino com irrigação artificial, que produzem frutos de ótima qualidade, sendo até exportados.

A utilização desses contra-argumentos revela uma estratégia textual por meio da qual o autor demonstra domínio do assunto discutido, de tal forma que consegue imaginar os possíveis argumentos de um leitor que discordaria do seu posicionamento, enriquecendo, assim, sua linha argumentativa. 
No final do último parágrafo, o candidato 1 sugere uma solução para o fato discutido: talvez se o povo tomasse consciência que tem voz, saberia falar mais alto, para que seu clamor chegasse até os governantes. Esses então, escutariam que o povo não quer depender de esmola, mas sim trabalhar e viver dignamente. Observemos que o autor confirma sua inserção na situação comunicativa inerente à prova, visto que, como acontece em geral nas dissertações escolares, produz uma conclusão sugestiva, conforme demonstra o uso do advérbio "talvez" seguido da conjunção "se", introduzindo uma alternativa à qual o povo poderia recorrer para solucionar os problemas focalizados no texto.

A argumentação apresentada pelo candidato 1 parece não ser consistente para sua inserção na situação proposta na prova: ele deveria produzir uma carta de reclamação, ou seja, deveria denunciar, protestar com relação aos problemas que estavam atingindo o homem do campo, tema indicado na prova. Não percebemos esse tom de denúncia e de persuasão, mas uma preocupação de argumentar sobre o assunto sem uma interlocução definida, prática letrada que satisfaz, em geral, as produções escolares, as quais, na maioria das vezes, são mais pautadas na exposição e no repasse de informações do que na argumentação e no posicionar-se frente aos fatos.

Portanto, o candidato 1 parece ter mobilizado, na redação de vestibular, práticas letradas advindas do letramento escolar, tendo em vista o abandono da situação comunicativa dada na prova e uma consequente adesão à situação inerente ao evento de letramento: troca-se a posição social de cidadão atuante da melhoria das condições do homem do campo para a de candidato produtor de dissertação escolar que escreve com fins avaliativos. Isso mesmo pôde ser verificado quando correlacionamos a redação produzida pelo candidato $2 \mathrm{com}$ o seu histórico de letramento. Vejamos a redação:

Ex.: 3

Sítio Rosinha, 17 de dezembro de 2006.

Caro leitor, 
Assim como vocês sou leitora da "Revista nordeste" e ao ver que será criada a seção "Cartas e Memórias" decidi denunciar aqui a minha indignação em relação a realidade da minha região.

Sou professora e me sinto constrangida com fatos aqui ocorrentes. Desde que cheguei ao Sítio Rosinha, vejo a falta de condição de sobrevivência de trabalhadores rurais, que aqui plantam e colhem, quando tem o que colher. Eles não tem energia, água e vivem em condições subumanas com altos índices de trabalho infantil e grandes jornadas de trabalho.

Para controlar tal situação, eu, junto com outros professores, organizamos o projeto "Por um nordeste melhor" que tem por objetivo protestar ao governo um aumento de verbas. Desde já gostaria de pedir a ajuda da revista para que, publicando tal denúncia, esta venha abrir os olhos da população e tentar desatar as mãos dos políticos que aqui governam, pois é inadmissível que o governo continue com os olhos vendados.

Atenciosamente,

T. C. B.

(Candidato 2 - Redação produzida no vestibular regular UFCG 2007)

Notamos, no exemplo 3, uma aparente inserção do candidato 2 na situação comunicativa proposta na prova, conforme sugere a reprodução da estrutura composicional do gênero carta - local, data, saudação inicial, interlocução com o destinatário, saudação final e assinatura. Estamos considerando uma aparente inserção porque, no corpo do texto, não há uma argumentação consistente, nenhum protesto, nenhuma denúncia de maneira a persuadir os leitores no tocante às condições de sobrevivência do homem do campo, temática da prova. Ainda que o candidato 2 tenha tentado persuadir a banca, fingindo participar da situação proposta, a essência do seu texto é escolar, sua participação efetiva dá-se na situação inerente ao evento prova de redação.

No primeiro parágrafo, o candidato 2 contextualiza sua carta, expondo seu objetivo - denunciar sua indignação quanto aos problemas que afligem a sua região. No parágrafo seguinte, justifica sua indignação quanto à falta de condição de sobrevivência dos trabalhadores rurais. 
Para tal, utiliza como argumento sua própria experiência no sítio Rosinha: plantam e colhem, quando tem o que colher. Eles não tem energia, água e vivem em condições subumanas com altos indices de trabalho infantil e grandes jornadas de trabalho. Argumentar a partir da própria experiência é uma estratégia produtiva, pelo fato de sugerir veracidade das informações. $\mathrm{O}$ fato é que só um argumento não é suficiente para problematizar a realidade da zona rural. Como persuadir o leitor a partir da exposição de apenas um argumento? $O$ não desenvolvimento da argumentação compromete a essência da carta protesto, consequentemente, o objetivo do texto não é atingido.

No último parágrafo, o candidato 2 diz a que alternativa recorreu para amenizar a situação emblemática do sítio - elaborou juntamente com outros professores o projeto "Por um Nordeste melhor", cuja finalidade foi protestar ao governo por um aumento de verbas. Ao afirmar o que já fez, o candidato 2 fere umas das práticas letradas requeridas pela carta- protesto, na qual, ao final do texto, o autor, geralmente, sugere algo que poderia ser feito, faz uma solicitação aos leitores e não relata o que já fora realizado.

$\mathrm{O}$ respeito à estrutura composicional do gênero carta e o enfraquecimento da linha argumentativa talvez possam ser explicados pelo histórico de letramento do candidato 2. Conforme entrevista, afirmou que

Registro 1

os professores diziam as características de cada redação e...assim...a como eu vou dizer a parte física também. A letra tem que ta bonita, tem que ta uma margem bem feita. Essas... as principais características. Ai... eles batiam muito nisso, assim, porque pelo menos nisso, assim, todo mundo tem... porque a... as várias estruturas de redação todo mundo tem que saber, né? Já que.. mesmo que o conteúdo não seja tão bom mas a estrutura pelo menos. [grifos nossos]

Tomando como base o trecho apresentado, sobretudo as partes destacadas, parece-nos que o candidato 2 produziu seu texto com base nas práticas letradas escolares repassadas pelo seu professor, haja vista 
que, ao citar os critérios focalizados nas aulas de redação, o candidato 2 destaca apenas aspectos formais, conforme nossos grifos. Chega a afirmar que a estrutura é mais importante que o conteúdo, assertiva confirmada na análise da carta que produziu no vestibular - demonstrou preocupação em reproduzir a estrutura da carta, mas não tratou nem argumentou sobre o tema indicado.

Nessa perspectiva, o letramento escolar parece ter se configurado como um elemento importante para que o candidato demonstrasse algumas práticas letradas requeridas pelo gênero carta, uma vez que afirmou na entrevista não ter sentido dificuldades para produzir a cartaprotesto, porque já a havia estudado na escola e porque eu tenho mais familiaridade com a carta.

Considerando que o candidato 2 enfatizou o estudo estrutural dos gêneros, que aparecem na agência escolar, podemos supor que ele tenha sido exposto à carta, de modo a favorecer a assimilação da estrutura e, consequentemente, realizar o processo de transposição de práticas letradas. O letramento escolar parece ter favorecido, assim, a participação do candidato 2 na situação inerente à prova, pois afirmou que escrevo apenas o que é solicitado na escola [grifos nossos]. O uso do termo destacado sugere-nos uma experiência restrita do candidato $2 \mathrm{com}$ as práticas letradas escolares, além de que parece confirmar o que os candidatos que não têm o hábito de escrever, que se limitam às práticas escolares, tendem a transpô-las para a prova de redação.

\section{CONSIDERAÇÕES FINAIS}

Considerando o primeiro objetivo traçado, evidenciamos que, pelo menos, três práticas letradas são requeridas na produção da cartaprotesto, quais sejam, adesão à situação comunicativa proposta na prova, adequação do texto ao tema proposto e uso do registro escrito formal da Língua Portuguesa. Essas práticas, especialmente a primeira, sinalizam o efeito retroativo dos novos estudos linguísticos sobre escrita - gêneros textuais e letramentos - na elaboração das propostas de redação apresentadas na prova referida. Há, desse modo, uma ampliação nas práticas letradas que até então eram solicitadas na maioria das provas de 
vestibular aplicadas no Brasil, as escolares (em geral, exige-se a escrita de uma dissertação).

Quanto ao segundo objetivo do presente artigo - correlação estabelecida entre as redações produzidas pelos candidatos e o seu histórico de letramento -, mostramos que um dos principais fatores que devem ter influenciado os candidatos a inserir-se na situação comunicativa inerente à prova, em detrimento da situação proposta na prova, foi, conforme a entrevista, a maior experiência com práticas letradas escolares frente às configuradas em outras agências. Disseram que produziam textos escolares e, em geral, o faziam tendo em vista as exigências da escola e/ou do vestibular.

Notamos que o aspecto social parece sobrepor-se ao individual, porque não há, de acordo com a entrevista, traços da história de vida dos sujeitos focalizados que pudessem interferir nas suas escolhas quanto à produção do gênero, bem como experiência com práticas letradas oriundas de outras agências que não a escolar, as quais pudessem ser transpostas para o evento prova de redação, já que as práticas que se configuram nos eventos, conforme Barton e Hamilton (2000), são relativamente estáveis, logo, não são exclusivas de um determinado evento de letramento.

Dessa forma, entendemos que a experiência social construída na agência escolar foi um elemento importante para que os candidatos abandonassem a situação proposta na prova e ingressassem na situação inerente a esse evento. Como os candidatos disseram ter mais familiaridade com as práticas escolares, o espaço socioletrado no qual essas práticas aparecem pode tê-los influenciado mais do que suas experiências individuais, as quais, como disseram, foram singulares, pontuais e pouco diversificadas.

\section{REFERÊNCIAS}

ALMEIDA, A. L. O professor-leitor, sua identidade e sua práxis. In: KLEIMAN, A. (Org.). A formação do professor. Campinas, São Paulo: Mercado de Letras, 2001. p. 115- 135.

ANDRÉ, M. E. D. A. de. Fundamentos da pesquisa etnográfica. In: Etnografia da prática escolar. Campinas, SP: Papirus, 1995. p. 15-69. 
BARTON, D.; HAMILTON, M. Literacy practices. In: BARTON, D.; HAMILTON, M.; IVANIC, R. Situated literacies. London e New York: Routledge, 2000. p. 07-15.

BAZERMAN, C. Escrita, gênero e interação social. DIONISIO, A.P.; HOFFANAGEL, J. C. (Orgs.). Escrita, gênero e interação social. São Paulo: Cortez, 2007.

GEE, J. P. The new literacy studies. In: BARTON, D.; HAMILTON, M.; IVANIC, R. (Eds).__. Situated literacies. Reading and writing in context. London: Routeledge, 2000. p. 180-197.

GUEDES-PINTO, A. L. Narrativas de práticas de leitura: trajetórias da professora alfabetizadora. In: KLEIMAN, A. (Org.). A formação do professor. Campinas, São Paulo: Mercado de Letras, 2001. p. 69-94.

GUEDES-PINTO, A. L. et al. Percursos de letramento dos professores: narrativas em foco In: KLEIMAN, A. B.; MATENCIO, M. de L. M. (Orgs.). Letramento e formação do professor - práticas discursivas, representações e construção do saber. Campinas, SP: Mercado de Letras, 2005 (Coleção Ideias sobre Linguagem). p. 65-92.

HEATH, S. B. Ways with words: language, life and work in communities and classrooms. Cambridge: Cambridge University Press, 1983.

KLEIMAN, A. B. (Org.). Os significados do letramento. Campinas, São Paulo: Mercado de Letras, 1995.

Formação do professor: retrospectivas e perspectivas na pesquisa. In: KLEIMAN, A. (Org.). A formação do professor. Campinas, SP: Mercado de Letras, 2001. p. 13-35.

. Leitura e prática social no desenvolvimento de competências no ensino médio. In: BUNZEN, C.; Mendonça, M. Português no ensino médio e formação de professor. São Paulo: Parábola, 2006.

LINO de ARAÚJO, D. Um "professor" no horário nobre: estudo da explicação em telejornais. 2004. 350f. Tese (Doutorado em Educação)Faculdade de Educação, Universidade de São Paulo, São Paulo, 2004. p. 128135.

LOPES, I. de A. Cenas de letramentos sociais. Recife: Programa de PósGraduação em Letras da UFPB, 2006. 221p.

MEY, J. L. Vozes da sociedade - Seminário de pragmática. Campinas, São Paulo: Mercado de Letras, 2001. 
ROJO, R. Letramento escolar em três práticas: perspectivas para a multivocalidade. Revista da ANPOLL, n. 11, jul./dez 2001. p. 235-262.

SCARAMUCCI, M. V. R. Propostas curriculares e exames vestibulares: potencializando o efeito retroativo benéfico no ensino de LE (Inglês). Contexturas, São José do Rio Preto, v. 5, 2001. p. 97-109.

SERCUNDES, M. M. I. Ensinado a escrever. In.: CHIAPPINI, L.; GERALDI, J.W. (Orgs.). Aprender e ensinar com textos. v. 1 São Paulo: Global, 1998. p. 21-39.

SIGNORINI, I. O relato autobiográfico na interação formador/formando. In.: KLEIMAN, A. B.; MATENCIO, M. de L. M. (Orgs.). Letramento e formação do professor - práticas discursivas, representações e construção do saber. Campinas, SP: Mercado de Letras, 2005 (Coleção Ideias sobre Linguagem). p. 93-126.

SILVA, E. M. da S. Histórico de letramento e práticas letradas em redações de vestibular. 2009. 171f. Dissertação (Mestrado em Linguagem e Ensino)—Programa de Pós-graduação em Linguagem e Ensino, Universidade Federal de Campina Grande, Campina Grande, 2009.

; LINO DE ARAÚJO, D. Redação e/ou gêneros textuais: caminhos de produção de textos no vestibular e no ensino médio. In: JORNADA NACIONAL DE ESTUDOS LINGÜÍSTICOS DO NORDESTE, 21., João Pessoa, PB. Anais... João Pessoa: UFPB, 2006a. p. 35-43.

Redação no vestibular e no ensino médio: um estudo sobre efeito retroativo. In: CONGRESSO DE INICIAÇÃO CIENTÍFICA, 3., Campina Grande, PB. Anais... Campina Grande: UFPB, 2006b. p. 34-44.

. Redação e/ou gêneros textuais: caminhos de produção de textos no vestibular e no ensino médio. In: JORNADA NACIONAL DE ESTUDOS LINGÜÍSTICOS DO NORDESTE, 21., João Pessoa, PB. Anais... João Pessoa: UFPB, 2006c.

Relato de experiência no vestibular da UFCG 2005: um estudo sobre as práticas de uso da escrita. In: SEMANA DE LETRAS DA UEPB: linguagens, tecnologia e ensino: a palavra (re)escrita e (re)lida, 13., Campina Grande, PB. Anais... Campina Grande: UEPB, 2006d.

Práticas letradas na redação de vestibular da UFCG. In: SEMINÁRIO SOBRE ENSINO DE LÍNGUA MATERNA E ESTRANGEIRA E DE LITERATURA, 4., Campina Grande, PB. Anais... Campina Grande: UFPB, 2005. 
. (Orgs). Redação de vestibular em questão - práticas, conceitos,

discursos e efeito retroativo. Campina Grande: Bagagem, 2010.

STREET, B. Literacy in theory and practice. Cambridge: Cambridge

University Press, 1984. p. 1-21.

UNICAMP. Pró-reitoria de Graduação. Comissão permanente para os

vestibulares. Vestibular Unicamp: redações 2003. Campinas, SP: Editora da Unicamp, 2003.

Recebido em 05/05/10. Aprovado em 23/08/10.

Title: Correlation between the protest letter genre and the candidate' literacy history: An analysis of the compositions for the university selection exams

Author: Elizabeth Maria da Silva; Denise Lino de Araújo

Abstract: Considering that some institutions, as the Universidade Federal de Campina Grande (UFCG), are now asking in the composition test that the candidates write a specific textual genre - and not, as before, a free style composition - in most of the exams to attend the university, the present paper aims at (1) assessing the required lettering practices in the production of a protest letter, as asked in the exam for the UFCG in 2007, and (2) investigate the correlation between the practices shown by the candidates in the production of the letter, and his/her lettering background. For such a goal, a descriptive-interpretive research was carried out, whose corpus was constituted by the test applied in the referred exam, as well as by a sample of the letters produced by the candidates, in addition to interviews with those candidates. The data were analyzed based on the studies on critical lettering (BATON; HAMILTON, 2000; GEE, 2000), and suggest that the lettering history of the candidates constitutes a decisive factor for the mobilization of lettered practices in compositions.

Keywords: Protest Letter. Lettered Practices. Literacy History. 